\title{
EFEITO DA ESCÓRIA, CALCÁRIO E NITROGÊNIO NA ABSORÇÃO DE SILÍCIO E NA PRODUÇÃO DO CAPIM-MARANDU $\left({ }^{1}\right)$
}

\author{
IVANA MACHADO FONSECA $\left({ }^{2 *}\right)$; RENATO DE MELLO PRADO $\left({ }^{3}\right)$; ANELISA DE AQUINO VIDAL $\left({ }^{4}\right)$; \\ THIAGO ASSIS RODRIGUES NOGUEIRA $\left({ }^{5}\right)$
}

\begin{abstract}
RESUMO
Objetivou-se, com este estudo, avaliar os efeitos da escória comparados ao calcário na presença de nitrogênio quanto à disponibilidade de silício no solo, no crescimento e na absorção de Si pela Brachiaria brizantha. Desenvolveu-se o estudo em casa de vegetação, realizando dois cortes no capim-marandu. Os tratamentos utilizados foram duas fontes de material corretivo (escória de siderurgia de aciaria e calcário dolomítico), três doses de material corretivo $\left(0,81 ; 1,61\right.$ e $3,22 \mathrm{~g} \mathrm{dm}^{-3}$ de $\left.\mathrm{ECaCO}_{3}\right)$, três doses de nitrogênio $\left(75,150\right.$ e $\left.300 \mathrm{mg} \mathrm{dm}^{-3}\right)$ e uma testemunha absoluta. Determinou-se a concentração de Si "disponível" no solo, a massa seca e os teores de Si e de $\mathrm{N}$ na parte aérea da forrageira. Verificou-se que as doses de escória aumentaram as concentrações de Si no solo e na planta, diminuindo, porém, o acúmulo de $\mathrm{N}$ no capim. O calcário não afetou a absorção de Si no primeiro corte, porém, diminuiu no segundo. A adubação nitrogenada associada à escória incrementa a produção de massa seca e a absorção de Si pelo capimmarandu.
\end{abstract}

Palavras-chave: Brachiaria brizantha, silicato de cálcio, resíduo siderúrgico.

\section{ABSTRACT \\ EFFECT OF SLAG, LIME AND NITROGEN IN SILICON ABSORPTION AND PRODUCTION OF THE MARANDU PALISADEGRASS}

This research was carried out in greenhouse conditions with the objective to evaluate the effects of slag and lime plus nitrogen on the soil silicon availability and growth and silicon absorption and growth of marandu palisadegrass (Brachiaria brizantha), with two cuts. The treatments were two corrective material types (slag and lime), three corrective material rates $\left(0.81 ; 1.61\right.$ and $3.22 \mathrm{~g} \mathrm{dm}^{-3}$ of $^{E_{C a C O}}$ ), three nitrogen rates $\left(75,150\right.$ and $\left.300 \mathrm{mg} \mathrm{dm}^{-3}\right)$ plus a control treatment, with four replications. The evaluated parameters were: available soil silicon, dry matter production and shoot silicon and nitrogen. Slag rates increased soil and plant silicon contents, but decreased plant nitrogen contents. Plant silicon uptake was not affected by lime in the first cutting, but it was reduced in the second cutting. Nitrogen fertilization plus slag increased dry matter yield and plant silicon contents.

Key words: Brachiaria brizantha, calcium silicate, metallurgy residue.

$\left({ }^{1}\right)$ Parte da Dissertação de Mestrado apresentada ao Programa de Pós-Graduação em Agronomia "Ciência do Solo", FCAV/ UNESP pela primeira autora. Recebido para publicação em 11 de julho de / 2007 e aprovado em 21 de outubro de 2008.

$\left({ }^{2}\right)$ Doutoranda em Agronomia "Produção Vegetal", FCAV/UNESP, Via de Acesso Prof. Paulo Donato Castellane, s/n. ${ }^{\circ}$ 14884-900 Jaboticabal (SP). Bolsista FAPESP. E-mail: ivanamfonseca@gmail.com (*) Autora correspondente.

$\left({ }^{3}\right)$ Departamento de Solos e Adubos, FCAV/UNESP, Jaboticabal (SP). Bolsista em Pesquisa do CNPq. E-mail: rmprado@fcav.unesp.br

$\left({ }^{4}\right)$ Agência Paulista de Tecnologia dos Agronegócios, Regional Centro-Oeste, Rua Andrade neves, 81, 1715-409 Marília (SP). E-mail: vidal@apta.sp.gov.br

$\left({ }^{5}\right)$ Doutorando em Ciências, CENA/USP, Caixa Postal 96, 13400-970 Piracicaba (SP). Bolsista FAPESP. E-mail: tarnogueira@gmail.com 


\section{INTRODUÇÃO}

O silício ( $\mathrm{Si}$ ) não faz parte dos elementos minerais essenciais para o desenvolvimento das plantas cultivadas, entretanto, promove maior produtividade em diversas culturas como as gramíneas (arroz, cana-de-açúcar, milho, trigo, sorgo, aveia, milheto e forrageiras) e muitas não-gramíneas como feijão, tomate, brássicas e alface (KORNDÖRFER e DATNOFF, 1995).

A ação benéfica do Si tem sido associada a diversos efeitos indiretos, dentre os quais, destacamse: o aumento na capacidade fotossintética, plantas mais eretas, redução da transpiração, aumento da resistência mecânica das células à invasão de fungos e ao ataque de insetos sugadores e mastigadores, diminuição do efeito tóxico do $\mathrm{Fe}$, Mn e outros metais pesados (Elawad e Green, 1979; Datnoff et al., 1991).

As fontes de Si promissoras para a agricultura são as escórias siderúrgicas, que têm sido utilizadas em alguns países como Japão e Estados Unidos (PRADO et al., 2001). No Brasil, as siderúrgicas estão localizadas, em sua maior proporção, na Região Sudeste, que coincide com a região de maior produção agrícola, portanto, a utilização da escória na agricultura não aumenta significativamente os custos quando comparado ao calcário, apesar deste ser mais bem distribuído no país.

Essas escórias são constituídas, basicamente, de silicato de cálcio e de magnésio (AmAral et al., 1994), o que lhes confere propriedade corretiva da acidez do solo semelhante à do calcário (PRADO et al., 2001), além de serem fontes de Si "disponível" (KORNDÖRFER et al., 2003). Entretanto, existem algumas diferenças entre os tipos de escórias em relação à disponibilidade desse elemento. As escórias de alto forno (subproduto da produção de ferro gusa), normalmente, possuem maiores concentrações de Si, todavia, com baixa solubilidade; nas de aciarias (subproduto da produção de aço) há menores concentrações de Si, porém, com maior solubilidade (Korndörfer et al., 2003; Pereira et al., 2007).

Os estudos sobre os efeitos da aplicação de Si em plantas, na forma de escória de siderurgia, quanto à absorção e produção das culturas, são escassos na literatura nacional, havendo trabalhos com a cultura do arroz (Pereira et al., 2004; Carvalho-Pupatto et al., 2004) e cana-de-açúcar (ANDERSON, 1991). Contudo, existem poucas pesquisas em plantas forrageiras (FORTES, 2006) e que relatam informações sobre a relação entre o silício e outros nutrientes, como o nitrogênio.

O efeito positivo do nitrogênio é conhecido no crescimento das plantas (Malavolta et al., 1997), entretanto, o incremento da adubação nitrogenada pode provocar redução nos teores de Si em plantas de arroz e aveia (WALLACE, 1989), e isto pode vir a causar incidência de doenças e diminuição da produção das culturas. Segundo Malavolta (2006), o silício proporciona às plantas maior possibilidade de resposta à adubação, principalmente, a nitrogenada.

Com este estudo, objetivou-se avaliar os efeitos da escória de siderurgia de aciaria comparados ao calcário na presença de nitrogênio, sobre a produção de massa seca e a absorção de silício pelas plantas de capim-marandu.

\section{MATERIAL E MÉTODOS}

O trabalho foi desenvolvido em casa de vegetação na FCAV/UNESP - Câmpus de Jaboticabal, no período de dezembro/2005 a junho/ 2006. Utilizou-se como planta-teste a Brachiaria brizantha (Hochst ex A.Rich) Stapf. cv. Marandu. O delineamento estatístico utilizado foi o de blocos ao acaso, em esquema fatorial $2 \times 3 \times 3+1$, sendo duas fontes de material corretivo, três doses de material corretivo, três doses de nitrogênio e uma testemunha absoluta, com quatro repetições, totalizando 76 unidades experimentais.

Cada unidade experimental foi constituída por um vaso preenchido com $4 \mathrm{dm}^{3}$ de um Latossolo Vermelho distrófico, textura média (EMBRAPA, 1999), e quatro plantas do capim-marandu.

O solo utilizado foi coletado na camada de 0 a $20 \mathrm{~cm}$ de profundidade, com as seguintes características: $\mathrm{pH}\left(\mathrm{CaCl}_{2}\right)=4,2 ; \mathrm{MO}=17 \mathrm{~g} \mathrm{dm}^{-3} ; \mathrm{P}$ $($ resina $)=5 \mathrm{mg} \mathrm{dm}^{-3} ; \mathrm{K}=0,5 \mathrm{mmol}_{\mathrm{c}} \mathrm{dm}^{-3} ; \mathrm{Ca}=4 \mathrm{mmol}_{\mathrm{c}}$ $\mathrm{dm}^{-3} ; \mathrm{Mg}=2 \mathrm{mmol}_{\mathrm{c}} \mathrm{dm}^{-3} ; \mathrm{H}+\mathrm{Al}=58 \mathrm{mmol}_{\mathrm{c}} \mathrm{dm}^{-3} ; \mathrm{SB}$ (soma de bases) $=6,5 \mathrm{mmol}_{\mathrm{C}} \mathrm{dm}^{-3}$; CTC ao pH 7,0 (capacidade de troca de cátions) $=64,5 \mathrm{mmol}_{\mathrm{c}} \mathrm{dm}^{-3}$; $\mathrm{V}$ (saturação por bases) $=10 \%$ e Si $\left(\mathrm{CaCl}_{2}\right)=4,0 \mathrm{mg}$ $\mathrm{dm}^{-3}$.

As fontes de material corretivo foram o calcário dolomítico $(\mathrm{PRNT}=75 \%, \mathrm{RE}=87 \%, \mathrm{CaO}=$ $40,23 \%$ e $\mathrm{MgO}=5,84 \%$, Si total $=6,8 \%$ e Si solúvel em $\mathrm{Na}_{2} \mathrm{CO}_{3}+\mathrm{NH}_{4} \mathrm{NO}_{3}=0,01 \%$ ) e a escória de siderurgia de aciaria fornecida pela empresa Dedini (PRNT = $54 \%, \mathrm{RE}=87 \%, \mathrm{CaO}=25,70 \%, \mathrm{MgO}=6,40 \%$, Si total $=$ $9,2 \%$ e $\mathrm{Si}$ solúvel em $\mathrm{Na}_{2} \mathrm{CO}_{3}+\mathrm{NH}_{4} \mathrm{NO}_{3}=1,9 \%$ ), aplicados no experimento tal qual. As doses dos materiais corretivos utilizadas foram: metade, uma vez e duas vezes a dose indicada para elevar $\mathrm{V}$ a $60 \%$, correspondentes, em equivalente $\mathrm{CaCO}_{3}$, a 0,81; 1,61 e $3,22 \mathrm{~g} \mathrm{dm}^{-3}$, respectivamente. Adotou-se $\mathrm{V}=60 \%$, uma vez que é considerada ideal para a cultura da Brachiaria brizantha no Estado de São Paulo, segundo WERNER et al. (1997). 
Os materiais corretivos, em suas respectivas doses, foram homogeneizados e incubados com as amostras dos solos por 90 dias, mantendo-se a umidade a $60 \%$ da capacidade de retenção. A perda de umidade dos vasos foi monitorada diariamente, repondo-se com água deionizada a quantidade evaporada.

Após o período de incubação do solo com os materiais corretivos, realizou-se a adubação básica aplicando-se $305 \mathrm{mg} \mathrm{dm}^{-3}$ de $\mathrm{P}$ na forma de superfosfato simples (granulometria fina), conforme recomendação de MEsQuita et al. (2004), e para os demais nutrientes, a recomendação seguiu as indicações de BonfIM et al. (2004), aplicando-se 200 $\mathrm{mg} \mathrm{dm}{ }^{-3}$ de $\mathrm{K}$ (KCl p.a.), 1,2 $\mathrm{mg} \mathrm{dm}^{-3}$ de $\mathrm{Cu}$ $\left(\mathrm{CuSO}_{4} \cdot 5 \mathrm{H}_{2} \mathrm{O}\right.$ p.a. $), 0,8 \mathrm{mg} \mathrm{dm}^{-3}$ de $\mathrm{B}\left(\mathrm{H}_{3} \mathrm{BO}_{3}\right.$ p.a. $), 1,5$ $\mathrm{mg} \mathrm{dm}^{-3}$ de Fe $\left(\mathrm{Fe}_{2}\left(\mathrm{SO}_{4}\right)_{3} .4 \mathrm{H}_{2} \mathrm{O}\right.$ p.a. $), 3,5 \mathrm{mg} \mathrm{dm}^{-3} \mathrm{de}$ $\mathrm{Mn}\left(\mathrm{MnCl}_{2} \cdot 6 \mathrm{H}_{2} \mathrm{O}\right.$ p.a. $), 0,15 \mathrm{mg} \mathrm{dm}^{-3}$ de $\mathrm{Mo}$ $\left(\mathrm{NaMoO}_{4} \cdot 2 \mathrm{H}_{2} \mathrm{O}\right.$ p.a.) e $4 \mathrm{mg} \mathrm{dm}{ }^{-3}$ de $\mathrm{Zn}\left(\mathrm{ZnSO}_{4} \cdot 7 \mathrm{H}_{2} \mathrm{O}\right.$ p.a.).

As doses de nitrogênio utilizadas antes do primeiro cultivo das plantas foram: 75,150 e $300 \mathrm{mg}$ $\mathrm{dm}^{-3}$ de $\mathrm{N}$, correspondendo à metade, à dose e duas vezes a dose recomendada por MesQuita et al. (2004), aplicadas superficialmente com posterior irrigação. Durante o primeiro cultivo, as doses de nitrogênio foram parceladas, sendo parte aplicada na semeadura (40\%) e o restante $(60 \%)$ aos 30 dias após a semeadura. Após o corte do primeiro cultivo e passados 10 dias da emergência dos brotos, utilizou-se, como dosepadrão, $50 \mathrm{mg} \mathrm{dm}^{-3}$ de $\mathrm{N}$ aplicados em cobertura, conforme cada tratamento (metade, a dose e duas vezes a dose recomendada), totalizando, assim, 100, 200 e $400 \mathrm{mg} \mathrm{dm}^{-3}$ de $\mathrm{N}$ antes do segundo corte. Como fonte de nitrogênio, utilizou-se a uréia para os dois cultivos.

Realizou-se a semeadura do capim-marandu em 23/3/2006 e, após a emergência, foram feitos desbastes deixando quatro plantas por vaso. A irrigação foi feita pelo método de pesagem dos vasos, mantendo a umidade correspondente a $60 \%$ da capacidade de retenção, utilizando-se água deionizada.

Os cortes da parte aérea da forrageira foram realizados a aproximadamente $10 \mathrm{~cm}$ da superfície do solo aos 48 e 96 dias após a semeadura (11/5 e 29/ $6 / 2006$ respectivamente). A amostragem da parte aérea correspondeu ao tecido vegetal utilizado para diagnose foliar (brotações e folhas novas), segundo a indicação de WERnER et al. (1997).

Após cada corte das plantas, o material vegetal foi lavado em água corrente, solução detergente neutro $\left(1 \mathrm{~mL} \mathrm{~L}^{-1}\right)$ e duas vezes em água deionizada. Em seguida, foi seco em estufa de circulação forçada de ar $\left(65-70{ }^{\circ} \mathrm{C}\right)$ até atingir massa constante para obtenção da produção de massa seca da parte aérea. Em seguida, as plantas foram moídas e as amostras foram submetidas à determinação de $\mathrm{N}$ e de Si, conforme metodologia descrita por BATAGLIA et al. (1983).

Foram realizadas amostragens de solo após o período de incubação e após os dois cortes das plantas de capim-marandu para determinação da concentração de silício "disponível" no solo, utilizando-se o método de extração com cloreto de cálcio 0,01 mol L ${ }^{-1}$ proposta por KoRNDÖRfER et al. (2004). Após a obtenção do extrato, as amostras foram deixadas em repouso por uma hora, realizando-se, posteriormente, a leitura do Si em espectrofotômetro no comprimento de onda de 660 nm (Kilmer, 1965).

Com os resultados, realizou-se a análise de variância, seguindo-se da aplicação do teste de Tukey a $5 \%$ de probabilidade para comparação das médias nos casos em que o teste F foi significativo. Também foram feitas análises de regressão polinomial para as interações significativas das fontes e doses (EsTAT, 1994), e ajuste ao modelo de superfície de resposta de segunda ordem às interações significativas das doses de material corretivo e doses de nitrogênio (SAS, 2002).

\section{RESULTADOS E DISCUSSÃO}

\section{Silício solúvel no solo}

De acordo com os dados obtidos, observou-se incremento significativo da concentração de silício "disponível" no solo nos tratamentos em relação à testemunha, em todas as épocas analisadas (Tabela 1). Houve acréscimo na concentração de Si de 50, 117 e $138 \%$ dos tratamentos em relação à testemunha no período pós-incubação, primeiro e segundo cortes das plantas de capim-marandu, respectivamente.

O menor teor de Si "disponível" no solo foi constatado nas testemunhas $\left(3,4\right.$ a 4,2 $\left.\mathrm{mg} \mathrm{dm}^{-3}\right)$, sendo esse valor referente ao silício já "disponível" no solo em estudo. Segundo Lima FilHo et al. (1999), a falta de uso de adubação silicatada associada à extração do Si por culturas acumuladoras contribuem para a diminuição dos teores desse elemento no solo.

Quanto às fontes de material corretivo analisadas, notou-se maior concentração de Si "disponível" no solo tratado com a escória de siderurgia em relação ao calcário, em todas as épocas de amostragem (Tabela 1). 
Tabela 1. Efeito dos tratamentos na concentração de silício no solo (extrator $\mathrm{CaCl}_{2} 0,01$ mol L $\mathrm{L}^{-1}$ ) após o período de incubação do solo com os materiais corretivos e a cada cultivo do capim-marandu

\begin{tabular}{|c|c|c|c|}
\hline \multirow{2}{*}{ Fontes $(\mathrm{F})$} & \multicolumn{3}{|c|}{ Concentração de Si no Solo } \\
\hline & Pós-Incubação & 1. ${ }^{\circ}$ Corte & 2. ${ }^{\circ}$ Corte \\
\hline & \multicolumn{3}{|c|}{$\mathrm{mg} \mathrm{dm}^{-3}$} \\
\hline Calcário Dolomítico & 4,2 & 7,4 & 7,2 \\
\hline Escória de Siderurgia & 8,6 & 9,7 & 9,1 \\
\hline Teste F & $781,99 * *$ & $156,85^{* *}$ & $77,76^{* *}$ \\
\hline dms (Tukey 5\%) & 0,33 & 0,38 & 0,41 \\
\hline \multicolumn{4}{|c|}{ Doses de Material Corretivo (DMC) } \\
\hline $\mathrm{D} 1\left(0,81 \mathrm{~g} \mathrm{dm}^{-3} \mathrm{ECaCO}_{3}\right)$ & 5,9 & 6,9 & 6,2 \\
\hline D2 $\left(1,61 \mathrm{~g} \mathrm{dm}^{-3} \mathrm{ECaCO}_{3}\right)$ & 6,6 & 8,5 & 7,9 \\
\hline D3 $\left(3,22 \mathrm{~g} \mathrm{dm}^{-3} \mathrm{ECaCO}_{3}\right)$ & 6,5 & 10,3 & 10,4 \\
\hline Teste F & $63,00^{* *}$ & $107,49^{* *}$ & $135,75^{* *}$ \\
\hline dms (Tukey 5\%) & 0,48 & 0,55 & 0,61 \\
\hline \multicolumn{4}{|l|}{ Doses de Nitrogênio $(\mathrm{N})\left({ }^{1}\right)$} \\
\hline D1 & - & 8,5 & 7,9 \\
\hline D2 & - & 8,4 & 7,9 \\
\hline D3 & - & 8,7 & 8,6 \\
\hline Teste F & - & $0,88^{\mathrm{NS}}$ & $5,38 * *$ \\
\hline dms (Tukey 5\%) & - & 0,55 & 0,61 \\
\hline Testemunha & 4,2 & 3,9 & 3,4 \\
\hline \multirow[t]{2}{*}{ Tratamentos } & 6,3 & 8,5 & 8,2 \\
\hline & & - Teste F & \\
\hline$(\mathrm{F}) \times(\mathrm{DMC})$ & $39,60 * *$ & $44,19^{* *}$ & $13,62^{* *}$ \\
\hline$(\mathrm{F}) \times(\mathrm{N})$ & - & $2,31^{\mathrm{NS}}$ & $1,07^{\mathrm{NS}}$ \\
\hline$(\mathrm{DMC}) \times(\mathrm{N})$ & - & $1,03^{\mathrm{NS}}$ & $6,98^{* *}$ \\
\hline Tratamentos vs Testemunha & $35,81^{* *}$ & $126,76^{* *}$ & $109,94^{* *}$ \\
\hline $\mathrm{CV}(\%)$ & 11,1 & 9,6 & 11,1 \\
\hline
\end{tabular}

**, ${ }^{*} \mathrm{e}^{\mathrm{NS}}$ - Significativo a $1 \%$ e $5 \%$ de probabilidade, e não-significativo respectivamente. $\left(^{1}\right)$ Doses de Nitrogênio: $1 .{ }^{\circ}$ corte $\left(\mathrm{D} 1=75 \mathrm{mg} \mathrm{dm}^{-3}, \mathrm{D} 2150 \mathrm{mg}\right.$ $\left.\mathrm{dm}^{-3}, \mathrm{D} 3=300 \mathrm{mg} \mathrm{dm}^{-3}\right) ; 2 .{ }^{\circ}$ corte $\left(\mathrm{D} 1=100 \mathrm{mg} \mathrm{dm}^{-3}, \mathrm{D} 2=200 \mathrm{mg} \mathrm{dm}^{-3}, \mathrm{D} 3=400 \mathrm{mg} \mathrm{dm}^{-3}\right)$.

Assim, observou-se que o uso da escória promoveu uma concentração de 8,6; 9,7 e 9,1 $\mathrm{mg} \mathrm{dm}^{-3}$ de Si para o período de pós-incubação do solo com os materiais corretivos e após o primeiro e segundo cortes do capim-marandu respectivamente.

Houve, ainda, efeito significativo das doses de material corretivo em todas as épocas analisadas. $\mathrm{Na}$ interação fontes e doses de material corretivo também se observou significância na concentração de Si "disponível" no solo. Assim, verificou-se que, em todas as amostragens do solo, houve efeito linear crescente com o aumento das doses de escória de siderurgia $\left[\mathrm{Si}_{(\text {pós-incubação) }}=1,565 \mathrm{ECaCO}_{3}+5,623 ; \mathrm{F}=\right.$ $112,54^{* *} ; \mathrm{R}^{2}=0,92 ; \mathrm{Si}_{\left(1^{\circ} \text { corte }\right)}=2,195 \mathrm{ECaCO}_{3}+5,585$; $\mathrm{F}=215,65^{* *} ; \mathrm{R}^{2}=0,99 ; \mathrm{Si}_{\left(2^{\circ} \text { corte }\right)}=1,998 \mathrm{ECaCO}_{3}+5,302$; $\left.\mathrm{F}=94,99^{* *} ; \mathrm{R}^{2}=0,98\right]$, ao passo que, com a aplicação do calcário, observou-se um ajuste linear pouco expressivo no período pós-incubação $(\mathrm{Si}=$ $\left.0,199 \mathrm{ECaCO}_{3}+3,649 ; \mathrm{F}=28,87^{* *} ; \mathrm{R}^{2}=0,99\right)$ e, quadráticos no $1 .{ }^{\circ}$ corte $\left(\mathrm{Si}=-0,814 \mathrm{ECaCO}_{3}{ }^{2}+\right.$ $\left.3,895 \mathrm{ECaCO}_{3}+3,729 ; \mathrm{F}=12,93^{* *} ; \mathrm{R}^{2}=1,00\right)$ e $2 .{ }^{\circ}$ corte $\left(\mathrm{Si}=-0,983 \mathrm{ECaCO}_{3}{ }^{2}+5,462 \mathrm{ECaCO}_{3}+1,429 ; \mathrm{F}=4,65^{*}\right.$; $\mathrm{R}^{2}=1,00$ ), sendo as doses 2,39 e $2,78 \mathrm{~g} \mathrm{dm}^{-3} \mathrm{de} \mathrm{ECaCO}_{3}$ as que proporcionaram maior concentração de $\mathrm{Si}$ "disponível" no solo com o uso de calcário para o $1^{\circ}$ e $2^{\circ}$ cortes, respectivamente. Nota-se pelo coeficiente angular das retas obtidas para a concentração de $\mathrm{Si}$ "disponível" no solo pós-incubação, em função da aplicação dos materiais corretivos, que a escória de siderurgia promoveu incremento de Si "disponível" oito vezes maior que o calcário dolomítico, atingindo o valor de $10,7 \mathrm{mg} \mathrm{dm}^{-3}$ de Si no solo.

O ligeiro aumento da concentração de Si "disponível" no solo devido à aplicação de calcário, 
provavelmente, ocorreu em decorrência do aumento do $\mathrm{pH}$ que proporcionou a liberação do Si existente no solo. Oliveira et al. (2007), avaliando o acúmulo de $\mathrm{Si}$ em arroz em diferentes condições de $\mathrm{pH}$ da rizosfera, verificaram que quanto maior foi o $\mathrm{pH}$ obtido, maior foi a disponibilidade do Si no solo e maior o seu teor na planta de arroz.

A interação fontes de material corretivo e doses de nitrogênio para os dois cortes da forrageira não foi significativa, assim, observou-se que os efeitos da adubação nitrogenada na concentração de Si no solo foram semelhantes com a presença ou não do Si no material corretivo. MAUAD et al. (2003), trabalhando com doses de Si e de N no solo cultivado com plantas de arroz, não constataram influência significativa das doses de $\mathrm{N}$ nas concentrações de Si "disponível" $\left[\mathrm{Si}(\mathrm{OH})_{4}\right]$ no solo. Segundo esses autores, o $\mathrm{Si}(\mathrm{OH})_{4}$ é um ácido fraco, de pequena força iônica e que, estando em solução, não compete com o nitrato por sítios de ligações no solo.

Nota-se que, apenas no $2{ }^{\circ}$ corte, a interação das doses de $\mathrm{N}$ e das doses de material corretivo foi significativa (Tabela 1), sendo a combinação de 3,22 g dm ${ }^{-3}$ de $\mathrm{ECaCO}_{3}$ e $400 \mathrm{mg} \mathrm{dm}^{-3}$ de $\mathrm{N}$ a que proporcionou maior concentração de Si no solo (10,9 $\left.\mathrm{mg} \mathrm{dm}{ }^{-3}\right)\left(\mathrm{Si}=4,1203+2,6349 \mathrm{ECaCO}_{3}-0,0025 \mathrm{~N}-\right.$ $0,2384 \mathrm{ECaCO}_{3}{ }^{2}+0,0002 \mathrm{ECaCO}_{3} \cdot \mathrm{N}+9,1667 \mathrm{E}-6 \mathrm{~N}^{2}$; $\left.\mathrm{F}=6,08^{*} ; \mathrm{R}^{2}=0,91\right)$. Logo, observou-se que a aplicação dos materiais corretivos incrementou a concentração de Si "disponível" no solo, especialmente, na maior dose de N. Esse processo ocorreu, provavelmente, devido à acidificação do solo pela adubação nitrogenada (RAIJ, 1991), pois, essa reação ácida favorece a solubilização dos silicatos e, consequentemente, o aumento na concentração de silício no solo (AlCARDE, 1992).

\section{Produção de massa seca da parte aérea do capim-marandu}

Observou-se em todas as épocas analisadas, efeito significativo entre os tratamentos e a testemunha. Para a massa seca da parte aérea, verificou-se, com a aplicação dos materiais corretivos e do nitrogênio, aumento de $115 \%$ e $295 \%$ dos tratamentos em relação à testemunha, respectivamente, no primeiro e segundo cortes (Tabela 2).

Observou-se, também, que a produção de massa seca do capim-marandu foi maior no segundo corte em relação ao primeiro. Pode-se atribuir essa diferença de produção entre os cortes, ao fato de no primeiro crescimento a planta destinar mais energia para a formação e o estabelecimento da estrutura da parte aérea e do sistema radicular. No segundo crescimento, a planta tinha todo o sistema radicular formado, podendo destinar mais energia para a produção e manutenção da parte aérea. Esse mesmo comportamento foi constatado no $2 .^{\circ}$ corte por SANTOS (1999) estudando o capim-braquiária (Brachiaria decumbens) e por LAVRes Júnior (2001) com o capimmombaça (Panicum maximum).

No $1 .^{\circ}$ corte, a produção de massa seca da parte aérea não diferiu entre as fontes de material corretivo testadas, revelando que com o uso de calcário dolomítico ou escória de siderurgia os efeitos foram semelhantes aos 48 dias. Entretanto, houve efeito significativo das doses de material corretivo e das doses de nitrogênio na produção de massa seca das plantas do capim-marandu. Logo, a interação entre os todos os fatores estudados foi significativa (Tabela 2).

Tabela 2. Produção de massa seca do capim-marandu no primeiro e no segundo cortes em função dos tratamentos estudados

\begin{tabular}{|c|c|c|}
\hline \multirow{2}{*}{ Fontes $(\mathrm{F})$} & \multicolumn{2}{|c|}{ Massa Seca } \\
\hline & 1. ${ }^{\circ}$ Corte & 2. ${ }^{\circ}$ Corte \\
\hline & \multicolumn{2}{|c|}{ g planta $^{-1}$} \\
\hline Calcário Dolomítico & 1,39 & 2,69 \\
\hline Escória de Siderurgia & 1,45 & 2,53 \\
\hline Teste F & $1,21^{\mathrm{NS}}$ & $12,26^{* *}$ \\
\hline dms (Tukey 5\%) & 0,11 & 0,09 \\
\hline \multicolumn{3}{|c|}{ Doses de Material Corretivo (DMC) } \\
\hline D1 $\left(0,81 \mathrm{~g} \mathrm{dm}^{-3} \mathrm{ECaCO}_{3}\right)$ & 1,58 & 2,60 \\
\hline D2 $\left(1,61 \mathrm{~g} \mathrm{dm}^{-3} \mathrm{ECaCO}_{3}\right)$ & 1,38 & 2,47 \\
\hline D3 $\left(3,22 \mathrm{~g} \mathrm{dm}^{-3} \mathrm{ECaCO}_{3}\right)$ & 1,30 & 2,76 \\
\hline Teste F & $8,59 * *$ & $13,40^{* *}$ \\
\hline dms (Tukey 5\%) & 0,17 & 0,14 \\
\hline \multicolumn{3}{|l|}{ Doses de Nitrogênio $(\mathrm{N})\left({ }^{1}\right)$} \\
\hline D1 & 1,14 & 2,03 \\
\hline D2 & 1,49 & 2,69 \\
\hline D3 & 1,63 & 3,11 \\
\hline Teste F & $27,36^{* *}$ & $186,77^{* *}$ \\
\hline dms (Tukey 5\%) & 0,17 & 0,14 \\
\hline Testemunha & 0,66 & 0,66 \\
\hline Tratamentos & 1,42 & 2,61 \\
\hline (F) $X(\mathrm{DMC})$ & $3,59 *$ & $8,88^{* *}$ \\
\hline$(\mathrm{F}) \mathrm{X}(\mathrm{N})$ & $4,73^{*}$ & $0,49^{\mathrm{NS}}$ \\
\hline$(\mathrm{DMC}) \times(\mathrm{N})$ & $3,58^{*}$ & $8,11^{* *}$ \\
\hline Tratamentos vs Testemunha & $38,71^{* *}$ & $381,62 * *$ \\
\hline CV (\%) & 17,3 & 7,8 \\
\hline
\end{tabular}

**, * $\mathrm{e}^{\mathrm{NS}}$ - Significativo a $1 \%$ e $5 \%$ de probabilidade, e não-significativo respectivamente. $\left(^{1}\right)$ Doses de nitrogênio: $1 .^{\circ}$ corte $\left(\mathrm{D} 1=75 \mathrm{mg} \mathrm{dm}^{-3}, \mathrm{D} 2=\right.$ $\left.150 \mathrm{mg} \mathrm{dm}^{-3}, \mathrm{D} 3=300 \mathrm{mg} \mathrm{dm}^{-3}\right) ; 2^{\circ}{ }^{\circ}$ corte $\left(\mathrm{D} 1=100 \mathrm{mg}^{=} \mathrm{dm}^{-3}, \mathrm{D} 2=200 \mathrm{mg}\right.$ $\left.\mathrm{dm}^{-3}, \mathrm{D} 3=400 \mathrm{mg} \mathrm{dm}^{-3}\right)$. 
No tratamento com escória de siderurgia não houve diferença com aumento das doses de material corretivo, todavia, no tratamento com calcário dolomítico, observou-se decréscimo linear na produção de massa seca (Figura 1a). Portanto, a menor dose de calcário aplicada, ou seja, a metade da dose recomendada foi suficiente para obter a maior produção de massa seca no primeiro corte das plantas. FORTES (2006) observou que o $\mathrm{V} \%$ baixo (24-29\%) para o capim-marandu foi suficiente para obter maior produção de massa seca da parte aérea. Desses resultados, pode-se inferir que o capim-marandu é de alta adaptação a solos com reação ácida, fato amplamente relatado na literatura (MonteIro e EuCLIDES, 2005).
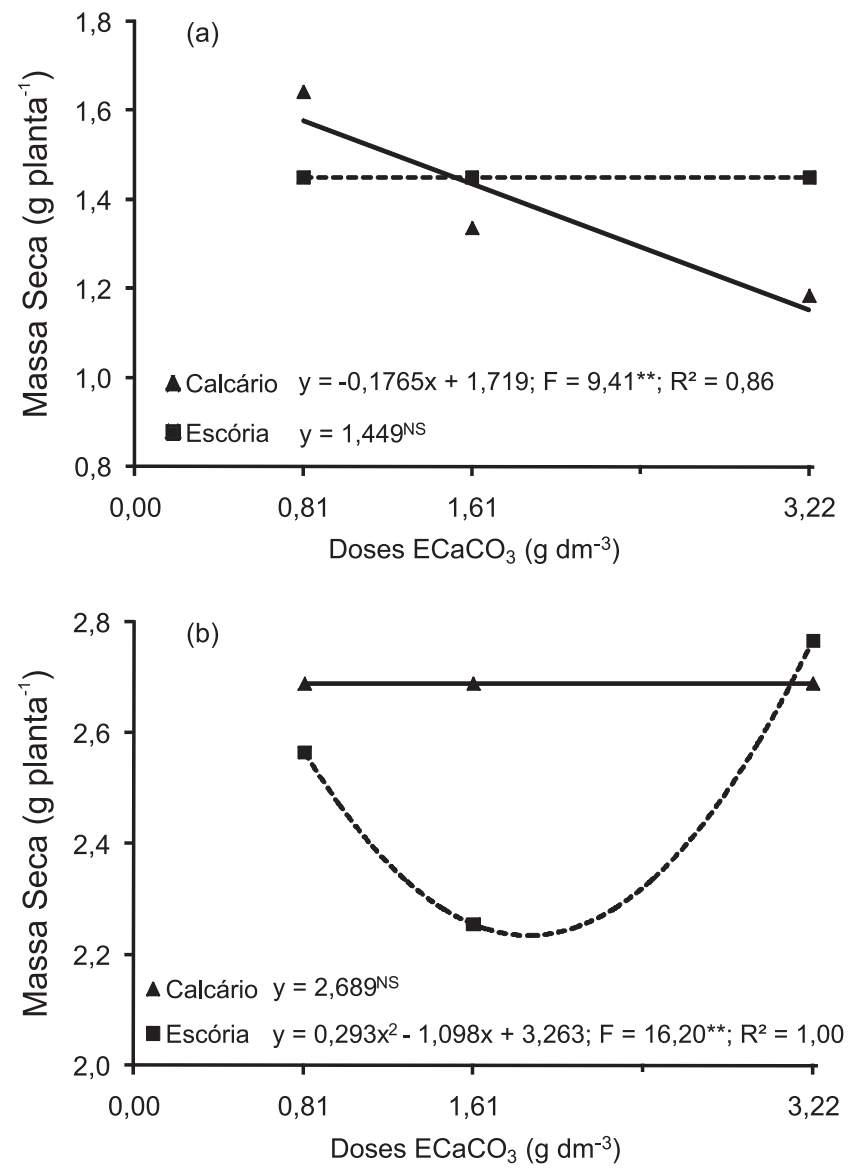

Figura 1. Produção de massa seca do capim-marandu em função das fontes e doses de material corretivo no primeiro (a) e segundo (b) cortes. FCAV/UNESP, Jaboticabal (SP), 2006.

Ainda no $1 .^{\circ}$ corte, as doses de nitrogênio associadas à escória de siderurgia, promoveram aumento linear na produção de massa seca das plantas (Massa seca $\left.=0,0028 \mathrm{~N}+0,96 ; \mathrm{F}=39,4^{* *} ; \mathrm{R}^{2}=0,96\right)$ e, com o uso do calcário, houve efeito quadrático (Massa Seca $\left.=-2 \mathrm{E}-05 \mathrm{~N}^{2}+0,010 \mathrm{~N}+0,49 ; \mathrm{F}=5,43^{*} ; \mathrm{R}^{2}=1,00\right)$, atingindo ponto de máximo na dose de $250 \mathrm{mg} \mathrm{dm}^{-3}$ de $\mathrm{N}$, mostrando com isso, efeito benéfico do silício e uma associação positiva da adubação silicatada e nitrogenada. Essa maior resposta da forrageira à aplicação de nitrogênio em solo com uso do silício também foi relatada por Malavolta (2006), pois, segundo este autor, o Si torna as folhas mais eretas, diminuindo o auto-sombreamento, com melhoria na interceptação da luz e na fotossíntese, minimizando o acamamento das plantas causado por altas aplicações de $\mathrm{N}$ que tornam os tecidos vegetais mais tenros, ocasionando queda na produtividade da cultura.

Salienta-se que o incremento da massa seca da parte aérea com a adubação nitrogenada foi reflexo do efeito deste nutriente no número de folhas, no número de perfilhos, na altura e na área foliar (dados não apresentados). Este efeito positivo do nitrogênio no crescimento de braquiárias foi relatado por outros autores (HofFMANN, 1992; SANTOS, 1997), e isto ocorre devido ao papel do $\mathrm{N}$ na nutrição das plantas, pois, segundo Malavolta et al. (1997), o N, tendo função estrutural, participa de diversos componentes orgânicos das plantas, como aminoácidos, proteínas e enzimas vitais para o crescimento vegetal.

Em relação ao $2 .^{\circ}$ corte, verificou-se efeito significativo para todos os fatores analisados na produção de massa seca da parte aérea. As interações, fontes e doses de material corretivo e doses de material corretivo com doses de $\mathrm{N}$ foram significativas (Tabela 2).

Pela interação fontes e doses de material corretivo, não houve diferença com o aumento das doses de calcário no $2{ }^{\circ}$ corte, todavia, no tratamento com escória de siderurgia, observou-se ajuste quadrático na produção de massa seca da parte aérea com o aumento das doses, sendo a dose $3,22 \mathrm{~g} \mathrm{dm}^{-3}$ de $\mathrm{ECaCO}_{3}$ aquela que proporcionou maior incremento na produção de massa seca (Figura 1b). Nota-se que a alta dose de material corretivo na forma de escória não prejudicou o crescimento da forrageira no $1 .^{\circ}$ corte e até aumentou o crescimento no $2 .^{\circ}$ corte. O contrário ocorreu com emprego do calcário (Tabela 2). Este fato também foi relatado por PRADO et al. (2001) com a cultura da cana-de-açúcar durante os dois primeiros cortes. Provavelmente, pode ter ocorrido um desequilíbrio nutricional na planta, principalmente, no que se refere aos micronutrientes, devido à aplicação de altas doses de calcário.

Em relação à interação doses de material corretivo e doses de nitrogênio, observou-se que as doses $3,22 \mathrm{~g} \mathrm{dm}^{-3}$ de $\mathrm{ECaCO}_{3}$ e $400 \mathrm{mg} \mathrm{dm}^{-3}$ de $\mathrm{N}$ foram as que proporcionaram maior produção de massa seca por planta $(3,38 \mathrm{~g})$ (Massa Seca $=1,5779$ $0,6131 \mathrm{ECaCO}_{3}+0,0103 \mathrm{~N}+0,1413 \mathrm{ECaCO}_{3}{ }^{2}+$ $\left.0,0005 \mathrm{ECaCO}_{3} . \mathrm{N}-1,5132 \mathrm{E}-5 \mathrm{~N}^{2} ; \mathrm{F}=9,50^{*} ; \mathrm{R}^{2}=0,94\right)$. 


\section{Teor e o acúmulo de Si na parte aérea do capim-marandu}

Verificou-se decréscimo de 28 e $46 \%$ no teor de Si e acréscimo de 52 e $57 \%$ no acúmulo de Si nas plantas dos tratamentos em relação à testemunha no primeiro e segundo cortes, respectivamente (Tabela 3).

O teor de Si nas plantas do capim-marandu diminuiu com os tratamentos em função do efeito de diluição, pois, houve incremento no acúmulo de Si da forrageira (Tabela 3).

Quanto ao teor e ao acúmulo de silício nas plantas, nos dois cortes, verificou-se diferença entre as fontes e, também, efeito significativo da interação fontes e doses de material corretivo, indicando que os efeitos das fontes no teor e acúmulo de Si dependem das doses aplicadas (Tabela 3). Como era esperado, o uso da escória de siderurgia promoveu maior acúmulo desse elemento, pois, incrementou significativamente a concentração de Si no solo $(8,6$ a 9,7 $\mathrm{mg} \mathrm{dm}^{-3}$ ) e, haja vista que, em sua composição há o Si que se encontra na forma disponível para as plantas. Esses resultados concordam com os dados de outros autores que a aplicação da escória de siderurgia incrementou a absorção de Si em plantas de cana-de-açúcar (ANDERSON, 1991, RAID et al.,1992).

Pela interação fontes e doses de material corretivo para o teor de Si no $1 .^{\circ}$ corte, verificou-se efeito quadrático $(\mathrm{P}<0,01)$ para o calcário, sendo a dose 2,16 $\mathrm{g} \mathrm{dm}^{-3}$ de $\mathrm{ECaCO}_{3}$ aquela que proporcionou maior teor do elemento nas plantas $\left(8,9 \mathrm{~g} \mathrm{~kg}^{-1}\right)$, aumento linear $(\mathrm{P}<0,01)$ com o uso da escória de siderurgia, cuja maior dose proporcionou o teor de silício nas plantas de $11,3 \mathrm{~g} \mathrm{~kg}^{-1}$ (Figura 2a). Entretanto, para o acúmulo de Si, houve efeito significativo $(\mathrm{P}<0,05)$ apenas para a escória de siderurgia com as doses de material corretivo, ajustando-se ao modelo linear crescente (Figura 2b).

Tendo em vista a indicação de MA et al. (2001) quanto à concentração mínima de Si $\left(10,0 \mathrm{~g} \mathrm{~kg}^{-1}\right)$ para que uma planta seja considerada acumuladora de silício, apenas os tratamentos com uso da escória poderiam classificar o capim-marandu como tal. Todavia, vale ressaltar que os teores tomados como referência por esses autores são apenas do tecido foliar e, os resultados do presente estudo são provenientes da parte aérea, incluindo lâminas foliares, bainhas e colmos. Segundo KORNDÖRFER et al. (2005), o Si se acumula, principalmente, nas áreas de máxima transpiração, logo, acredita-se que, se fosse realizada análise apenas das folhas, como realizado por MA et al. (2001), poderiam ser obtidos valores mais elevados.
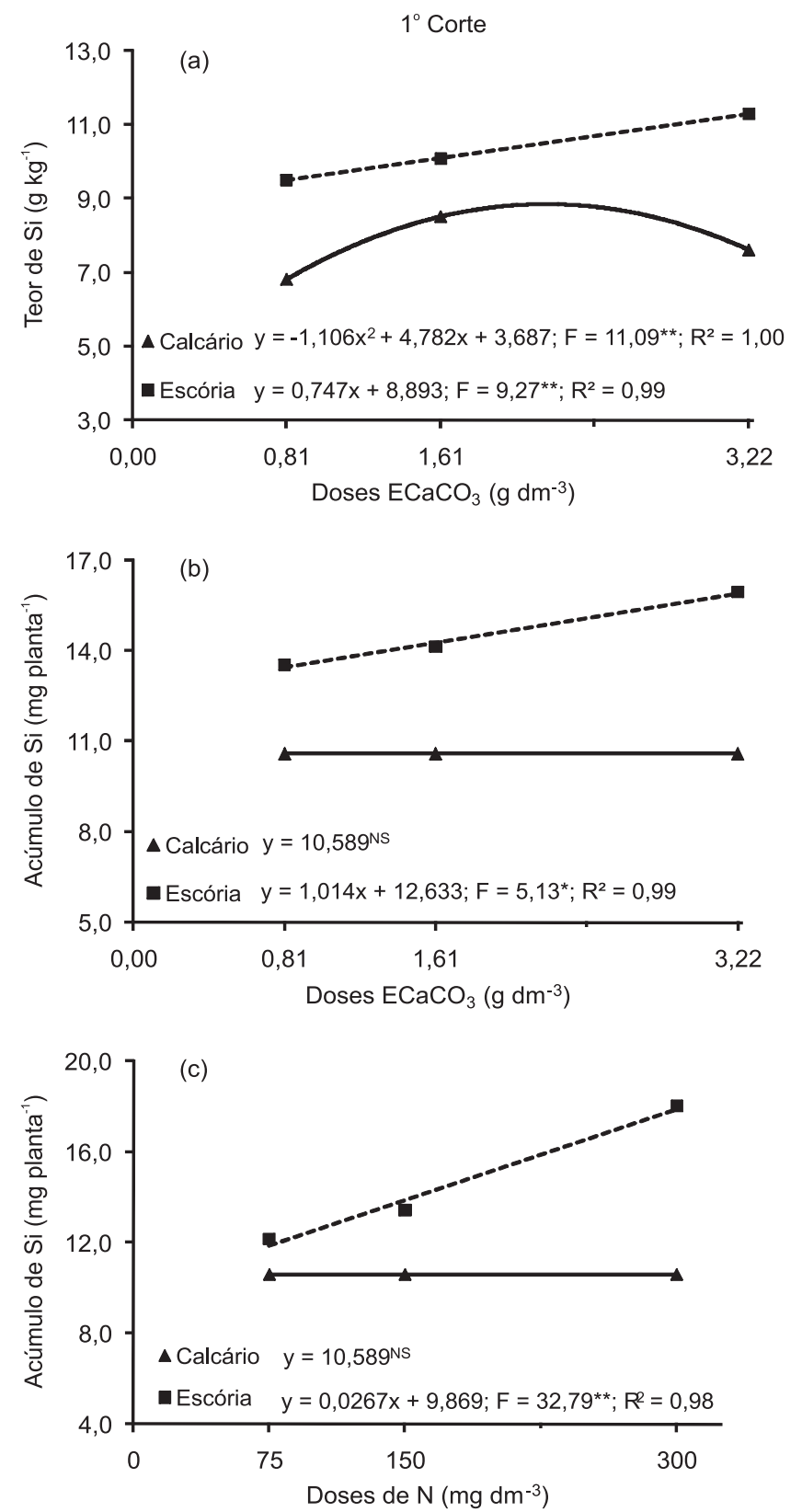

Figura 2. Teor (a) e acúmulo (b) de Si em função das fontes e das doses de material corretivo e, acúmulo de Si (c) em função das fontes de material corretivo e das doses de nitrogênio nas plantas de capim-marandu no primeiro corte. FCAV/UNESP, Jaboticabal (SP), 2006.

A ausência de resposta na produção de massa seca do capim-marandu no primeiro corte, provavelmente, ocorreu devido ao teor de silício ter atingido 11,3 $\mathrm{g} \mathrm{kg}^{-1}$ com a escória de siderurgia. Melo (2005), estudando a interação silício e fósforo em capim-marandu em Latossolo Vermelho-Amarelo, verificou máxima produção de massa seca com teor de $15,1 \mathrm{~g} \mathrm{~kg}^{-1}$ de Si na parte aérea das plantas no primeiro corte. 


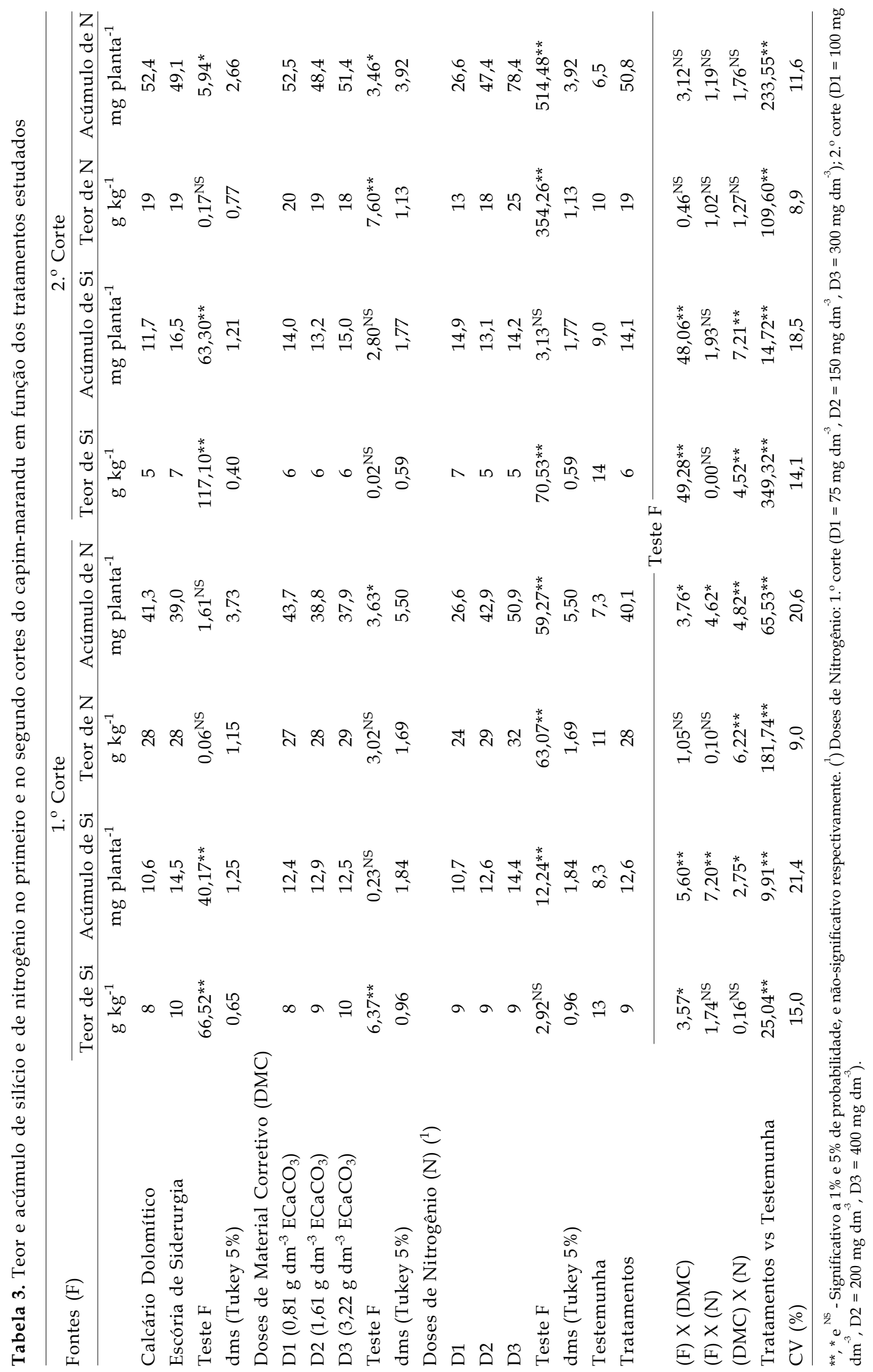


Ainda no $1 .^{\circ}$ corte, a interação fontes de material corretivo e doses de nitrogênio foi significativa para o acúmulo de $\mathrm{Si}$, ou seja, houve aumento linear $(P<0,01)$ em função das doses de $N$, apenas com a aplicação de escória de siderurgia (Figura 2c). Salienta-se que este incremento no acúmulo de Si ocorreu devido à maior produção de massa seca obtida com as doses de N (Tabela 2), uma vez que $\mathrm{N}$ participa de diversos processos na planta, dentre os quais a divisão celular e a constituição de tecidos.

Em se tratando da análise do $2^{\circ}$ corte das plantas do capim-marandu, verificou-se significância da interação fontes e doses de material corretivo no teor e acúmulo de Si nas plantas, observando-se efeito linear decrescente $(\mathrm{P}<0,01)$ para o calcário e efeito linear crescente $(\mathrm{P}<0,01)$ com o uso da escória de siderurgia (Figuras $3 \mathrm{a}, \mathrm{b}$ ). A maior dose da escória promoveu teor de $8,0 \mathrm{~g} \mathrm{~kg}^{-1}$ de Si nas plantas do capim-marandu.
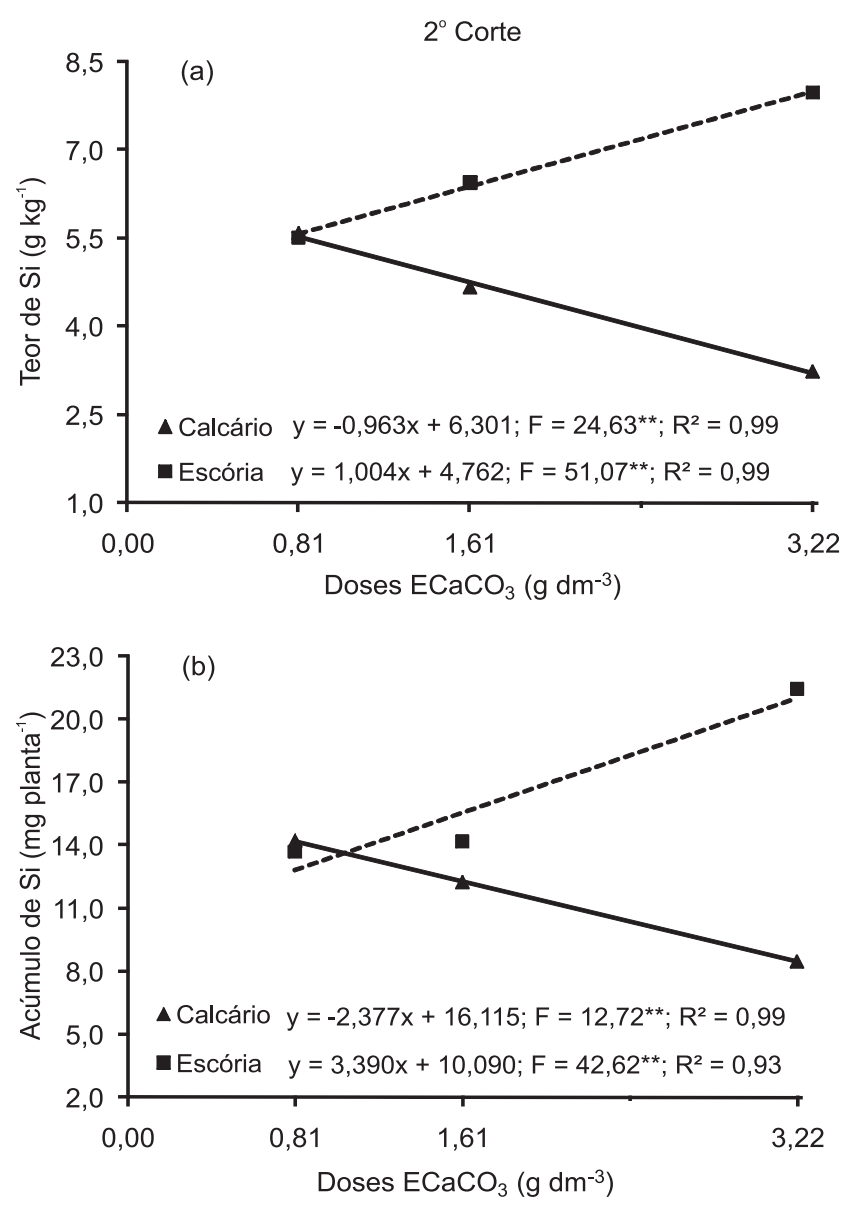

Figura 3. Teor (a) e acúmulo (b) de silício em plantas de capim-marandu em função das fontes e das doses de material corretivo no segundo corte. FCAV/UNESP, Jaboticabal-SP, 2006.
Estes resultados concordam parcialmente com FORTES (2006) que observou efeito significativo (ajuste linear) no teor de Si no capim-marandu em função da aplicação de silicato de cálcio e de magnésio apenas no segundo corte. Assim, no presente trabalho, a escória de siderurgia promoveu aumento linear no teor de Si no primeiro corte, pois, a escória foi incorporada 90 dias antes do plantio da forrageira, enquanto o período de incubação no trabalho de FORTES (2006) foi de apenas 30 dias antes do plantio.

A resposta na produção de massa seca do capim-marandu no $2 .^{\circ}$ corte em vista da aplicação da escória também ocorreu em virtude do teor de silício alcançado $\left(8,0 \mathrm{~g} \mathrm{~kg}^{-1}\right)$, o qual foi suficiente para a forrageira nesse corte (Figura 3a), visto que FORTES (2006) observou, ainda, para o capim-marandu, que a maior produção de massa seca da parte aérea esteve associada ao teor de $6,9 \mathrm{~g} \mathrm{~kg}^{-1}$ de Si nas plantas.

Observou-se, também, efeito significativo da interação doses de material corretivo e doses de nitrogênio no teor e no acúmulo de silício nas plantas do capim-marandu no $2 .^{\circ}$ corte; contudo, não houve ajuste a $10 \%$ de probabilidade para o modelo de superfície de resposta aplicado $\left(\mathrm{P}_{\text {teor }}=0,12 ; \mathrm{P}_{\text {acúmulo }}=\right.$ $0,91)$. Com isso, ao analisar o efeito isolado das doses de nitrogênio, detectou-se decréscimo no teor de $\mathrm{Si}$ nas plantas desse capim, à medida que aumentavam as doses de $\mathrm{N}$ no $2 .^{\circ}$ corte. Provavelmente, o decréscimo no teor de Si nas plantas, pode ser atribuído ao efeito de diluição provocado pelo N. Assim, o incremento na produção de massa seca da parte aérea, em virtude do aumento das doses de $\mathrm{N}$, não foi acompanhado de uma absorção de Si na mesma proporção, ocorrendo diminuição do teor desse elemento nas plantas. Comportamento semelhante foi apresentado por MAUAD et al. (2003) que obtiveram em plantas de arroz teores de Si mais pronunciados quando a adubação nitrogenada foi baixa, sendo esses resultados explicados pela competição que existe entre o $\mathrm{H}_{3} \mathrm{SiO}_{4}{ }^{-}$ e o $\mathrm{NO}_{3}{ }^{-}$pelos sítios de absorção da planta, conforme foi relatado por WALLACE (1989).

\section{capim-marandu \\ Teor e acúmulo de $\mathbf{N}$ da parte aérea do}

De acordo com os dados obtidos, observou-se que no $1 .^{\circ}$ e $2 .^{\circ}$ cortes houve efeito significativo dos tratamentos em relação à testemunha no teor e no acúmulo de nitrogênio nas plantas de capim-marandu (Tabela 3).

No $1 .^{\circ}$ corte, observou-se que apenas o fator nitrogênio proporcionou efeito no teor de $\mathrm{N}$ nas plantas; entretanto, a interação doses de material corretivo e doses de nitrogênio foi significativa (Tabela 3). 
Com a aplicação do nitrogênio, notou-se que o teor de $\mathrm{N}$ obtido no capim-marandu variou de 24 a $32 \mathrm{~g} \mathrm{~kg}^{-1}$ de $\mathrm{N}$ no $1 .^{\circ}$ corte. Werner et al. (1997) consideram adequado o teor de $\mathrm{N}=13-20 \mathrm{~g} \mathrm{~kg}^{-1}$ na parte aérea (brotação nova e folhas verdes) para Brachiaria brizantha.

Quanto à absorção de $\mathrm{N}$ pelo capim-marandu, notou-se que a aplicação dos materiais corretivos e do nitrogênio incrementou o acúmulo de $\mathrm{N}$ em $449 \%$ e $682 \%$ no $1 .^{\circ}$ e $2 .^{\circ}$ cortes, respectivamente, em relação à testemunha (Tabela 3). Esta melhoria da nutrição da planta com as doses de $\mathrm{N}$, explicaria o efeito deste nutriente na produção de massa seca.

Para o $1 .^{\circ}$ corte, verificou-se interação significativa entre todos os fatores analisados no acúmulo de $\mathrm{N}$ nas plantas. Pela interação fontes e doses de material corretivo, observou-se diferença apenas para o calcário, com modelo linear decrescente (Acúmulo $\mathrm{N}=-4,462 \mathrm{ECaCO}_{3}+47,35 ; \mathrm{F}=5,30^{*} ; \mathrm{R}^{2}=$ $0,78)$ no acúmulo de $\mathrm{N}$ quando se aumentaram as doses de calcário. Portanto, a menor dose de calcário aplicada $\left(0,81 \mathrm{~g} \mathrm{dm}^{-3}\right.$ de $\left.\mathrm{ECaCO}_{3}\right)$, ou seja, a metade da dosepadrão, foi suficiente para obter o maior acúmulo de nitrogênio pelas plantas $\left(43,7 \mathrm{mg}\right.$ planta $^{-1}$ de N$)$. Provavelmente, como as braquiárias são plantas tolerantes às condições de acidez no solo, as altas doses de calcário afetaram negativamente a produção de massa seca da forrageira (Tabela 2), podendo ter provocado uma desordem nutricional, diminuindo a absorção dos micronutrientes e, consequentemente, diminuindo a absorção de $\mathrm{N}$ pelas plantas.

Em se tratando da interação fontes de material corretivo e doses de nitrogênio, obteve-se um ajuste ao modelo quadrático no acúmulo de $\mathrm{N}$ para a fonte calcário (Acúmulo $\mathrm{N}=-0,001 \mathrm{ECaCO}_{3}{ }^{2}+0,452 \mathrm{ECaCO}_{3}$ $\left.-1,51 ; \mathrm{F}=7,24^{*} ; \mathrm{R}^{2}=1,00\right)$, atingindo o ponto máximo na dose de $226 \mathrm{mg} \mathrm{dm}^{-3}$ de $\mathrm{N}$ (49,6 $\mathrm{mg}_{\text {planta }}{ }^{-1}$ de N$)$. Por outro lado, com a escória de siderurgia o efeito linear foi crescente (Acúmulo $\mathrm{N}=0,128 \mathrm{ECaCO}_{3}+19,02$; $\left.\mathrm{F}=64,53^{* *} ; \mathrm{R}^{2}=0,96\right)$ no acúmulo de $\mathrm{N}$ no capimmarandu quando se aumentaram as doses de nitrogênio. A adubação nitrogenada na presença do silicato foi mais eficiente no aumento da absorção de $\mathrm{N}$ pelas plantas do que sem silicato ou na presença do calcário. Assim, o uso da maior dose de $\mathrm{N}$ na presença de Si garantiu maior absorção de N. Então, pôde-se inferir que Si aumentou a absorção de N, com um comportamento sinérgico entre os elementos, haja vista que houve correlação positiva da absorção de nitrogênio com a absorção de Si pelo capim-marandu (Figura 4).

Para o $2 .^{\circ}$ corte, como as interações não foram significativas entre os fatores no teor e no acúmulo de $\mathrm{N}$, analisou-se os fatores isoladamente e observouse, como no $1 .^{\circ}$ corte, que as fontes de material corretivo estudadas não afetaram o teor de $\mathrm{N}$ nas plantas. Entretanto, para o acúmulo de $\mathrm{N}$ nas plantas, houve diferença entre as fontes de material corretivo (Tabela $3)$, evidenciando maior acúmulo desse elemento $(52,4$ mg planta ${ }^{-1}$ de N) para o calcário, o que discorda de PRADO et al. (2002) que não obtiveram diferença entre o calcário calcítico e a escória de siderurgia no acúmulo de $\mathrm{N}$ na parte aérea da cana-soca.

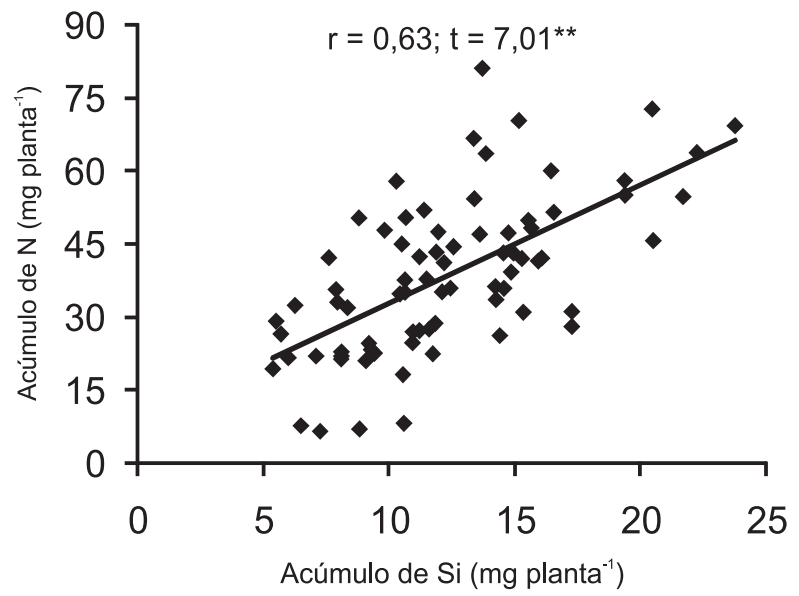

Figura 4. Relação entre o acúmulo de N e de Si pelas plantas de Brachiaria brizantha em todos os tratamentos no primeiro corte. FCAV/UNESP, Jaboticabal (SP), 2006.

Quanto às doses de material corretivo, observou-se, para o teor de $\mathrm{N}$ na parte aérea da gramínea, efeito linear decrescente $($ Teor $\mathrm{N}=-$ $\left.0,721 \mathrm{ECaCO}_{3}+20,041 ; \mathrm{F}=13,68^{* *} ; \mathrm{R}^{2}=0,94\right)$ e, para o acúmulo de $\mathrm{N}$ nas plantas, ajuste quadrático (Acúmulo $\mathrm{N}=2,917 \mathrm{ECaCO}_{3}{ }^{2}-12,252 \mathrm{ECaCO}_{3}+$ 60,$\left.555 ; \mathrm{F}=4,99^{*} ; \mathrm{R}^{2}=1,00\right)$. Constatou-se que a menor dose de material corretivo $\left(0,81 \mathrm{~g} \mathrm{dm}^{-3}\right.$ de $\left.\mathrm{ECaCO}_{3}\right)$ esteve associada ao maior teor e acúmulo de $\mathrm{N}$ nas plantas, o que, possivelmente, está relacionado ao efeito desse tratamento na maior produção de massa seca (Tabela 2).

Para as doses de nitrogênio, o comportamento foi o inverso; houve incremento linear no teor de $\mathrm{N}$, bem como no acúmulo desse elemento nas plantas $\left(\right.$ Teor $\mathrm{N}=0,040 \mathrm{~N}+9,187 ; \mathrm{F}=756,03^{* *} ; \mathrm{R}^{2}=0,99 \mathrm{e}$, Acúmulo $\mathrm{N}=0,170 \mathrm{~N}+11,044 ; \mathrm{F}=880,69^{* *} ; \mathrm{R}^{2}=0,99$ ).

\section{CONCLUSÕES}

1. A escória de siderurgia promove aumentos na concentração de Si no solo.

2. A presença ou não de Si no material corretivo quando associado à adubação nitrogenada não interfere na concentração de Si no solo. 
3. Os materiais corretivos diferenciaram-se apenas no $2 .^{\circ}$ corte, destacando-se a escória de siderurgia com incremento linear na absorção de Si e na produção de massa seca do capim-marandu.

4. A adubação nitrogenada associada à escória de siderurgia também aumenta a produção de massa seca e a absorção de Si pelo capim-marandu.

\section{AGRADECIMENTOS}

Ao $\mathrm{CNPq}$ pelo auxílio financeiro concedido (Edital Universal Proc. 470005/2004-1) e à CAPES pela bolsa de mestrado concedida à primeira autora.

\section{REFERÊNCIAS}

ALCARDE, J.C. Corretivos da acidez dos solos: características e interpretações técnicas. 2. ed. São Paulo: ANDA, 1992. 26p. (Boletim técnico 6)

AMARAL, A.S.; DEFELIPO, B.V.; COSTA, L.M.; FONTES, M.P.F. Liberação de Zn, Fe, Mn e Cd de quatro corretivos da acidez e absorção por alface em dois solos. Pesquisa Agropecuária Brasileira, Brasília, v.29, n.9, p.1351-1358, 1994.

ANDERSON, D.L. Soil and leaf nutrient interaction following application of calcium silicate slag to sugarcane. Fertilizer Research, The Netherlands, v.30, n.1, p.9-18, 1991.

BATAGLIA, O.C.; FURLANI, A.M.C.; TEIXEIRA, J.P.F.; FURLANI, P.R.; GALLO, J.R. Métodos de análise química de plantas. Campinas: Instituto Agronômico, 1983. 48p. (Boletim Técnico, 78)

BONFIM, E.M.S; FREIRE, F.J; SANTOS, M.V.F; SILVA, T.J.A; FREIRE, M.B.G.S. Níveis críticos de fósforo para Brachiaria brizantha e suas relações com características físicas e químicas em solos de Pernambuco. Revista Brasileira de Ciência do Solo, Viçosa, v.28, n.2, p.281-288, 2004.

CARVALHO-PUPATTO, J.G.; BULL, L.T.; CRUSCIOL, C.A. Atributos químicos do solo, crescimento radicular e produtividade do arroz de acordo com a aplicação de escórias. Pesquisa Agropecuária Brasileira, Brasília, v.39, n.12, p.12131218, 2004.

DATNOFF, L.E.; RAID, R.N.;SNYDER, G.H.; JONES, D.B. Effect of calcium silicate on blast and brown spot intensities and yields of rice. Plant Diseases, Beltsville, v.75, n.7, p.729-732, 1991.

ELAWAD, S.H.; GREEN JR., V.E. Silicon and the rice plant environment: a review of recent research. Il riso, Milano, v.28, n.3, p.235-253, 1979.

EMBRAPA. EMPRESA BRASILEIRA DE PESQUISA AGROPECUÁRIA. Sistema Brasileiro de Classificação de Solos. Brasília: Embrapa Produção de Informação; Rio de Janeiro: Embrapa Solos, 1999. 412 p.
ESTAT: Sistema de análises estatísticas. 1994. DCE - FCAV/ UNESP.

FORTES, C.A. Correção do solo com silicato de cálcio e magnésio para produção de gramíneas forrageiras. 2006. 137f. Dissertação (Mestrado em Solos e Nutrição de Plantas) Universidade Federal de Lavras, Lavras.

HOFFMANN, C.R. Nutrição mineral e crescimento de braquiária e de colonião, sob influência das aplicações de nitrogênio, fósforo, potássio e enxofre em Latossolo de região noroeste do Paraná. 1992. 204f. Dissertação (Mestrado em Zootecnia) - Universidade Federal de Lavras, Lavras.

KILMER, V.J. Silicon. In: BLACK, C.A.; EVANS, D.D.; WHITE, J.L.; ENSMINGER, L. E.; CLARK, F.E. (eds.). Methods of soil analysis: chemical and microbiological properties. Madison: American Society of Agronomy, 1965. p.959-962.

KORNDÖRFER, G.H.; DATNOFF, L.E. Adubação com silício: uma alternativa no controle de doenças na cana-de-açúcar e do arroz. Informações Agronômicas, Piracicaba, n.70, p.1-5, 1995.

KORNDÖRFER, G.H.; PEREIRA, H.S.; CAMARGO, M.S. Silicatos de cálcio e magnésio na agricultura. 2 ed. Uberlândia: GPSi-ICIAG-UFU, 2003. 53p. (Boletim Técnico, 1)

KORNDÖRFER, G.H.; PEREIRA, H.S.; NOLLA, A. Análise de silício: solo, planta e fertilizante. Uberlândia: GPSi-ICIAGUFU, 2004. 34p. (Boletim técnico, 2)

KORNDÖRFER, G.H.; NOLLA, A.; RAMOS, L.A. Available silicon tropical soils cropyield. In: SILICON IN AGRICULTURE CONFERENCE, 3., 2005, Uberlândia, Anais... Uberlândia: Universidade Federal de Uberlândia, 2005, p.77-84.

LAVRES JÚNIOR, J. Combinações de doses de nitrogênio e potássio para o capim-Mombaça. 2001. 155f. Dissertação (Mestrado em Solos e Nutrição de Plantas) - Escola Superior de Agricultura "Luiz de Queiroz", Universidade de São Paulo, Piracicaba.

LIMA FILHO, O.F.; LIMA, M.T.G.; TSAI, S.M. O silício na agricultura. 1999. p.1-7. (Encarte Técnico - Informe Agronômico, 87)

MA, J.F.; MIYAKE, Y.; TAKAHASHI, E. Silicon as a beneficial element for crop plants. In: SILICON IN AGRICULTURE CONFERENCE, 2., 2001, Amsterdam. Anais. Amsterdam: Elsevier, 2001. p.17-39.

MALAVOLTA, E.; VITTI, G.S.; OLIVEIRA, S.A. Avaliação do estado nutricional das plantas: princípios e aplicações. Piracicaba: POTAFOS, 1997.319p.

MALAVOLTA, E. Manual de nutrição mineral de plantas. São Paulo: Agronômica Ceres, 2006. 638p.

MAUAD, M.; GRASSI FILHO, H.; CRUSCIOL, C.A.C.; CORRÊA, J.C. Teores de silício no solo e na planta de arroz de terras altas com diferentes doses de adubação silicatada e nitrogenada. Revista Brasileira de Ciência do Solo, Viçosa, v.27, n.5, p.867-873, 2003. 
MELO, S.P. Silício e fósforo para o estabelecimento do capimMarandu num Latossolo Vermelho-Amarelo. 2005. 110f. Tese (Doutorado em Solos e Nutrição de Plantas) - Escola Superior de Agricultura "LuizdeQueiroz", UniversidadedeSãoPaulo, Piracicaba.

MESQUITA, E.E; PINTO, J.C; NETO, A.E. F; SANTOS, I.P.A; TAVARES, V.B. Teores críticos de fósforo em três solos para o estabelecimento de capim-mombaça, capim-marandu e capimandropogon em vasos. Revista Brasileira de Zootecnia, Viçosa, v.33, n.2, p.290-301, 2004.

MONTEIRO, F.A.; EUCLIDES, V.P.B. Adubação de plantas forrageiras na produção e qualidade forrageira. In: VOLUMOSOS NA PRODUÇÃO DE RUMINANTES, 1., 2005, Jaboticabal. Anais... Jaboticabal: Funep. 2005. p.159-186.

OLIVEIRA, L.A.; KORNDÖRFER, G.H.; PEREIRA, A.C. Acumulação de silício em arroz em diferentes condições de pH da rizosfera. Revista Brasileira de Ciência do Solo, Viçosa, v.31, n.4, p.685-690, 2007.

PEREIRA, H.S.; KORNDÖRFER, G.H.; VIDAL, A.A.; CAMARGO, M.S. Fontes de silício para a cultura do arroz. Scientia Agricola, Piracicaba, v.61, n.5, p.522-528, 2004.

PEREIRA, H.S.; BARBOSA, N.C.; CARNEIRO, M.A.C.; KORNDÖRFER, G.H. Avaliação de fontes e extratores de silício no solo. Pesquisa Agropecuária Brasileira, Brasília, v.42, n.2, p.239-247, 2007.

PRADO, R.M.; FERNANDES, F.M.; NATALE, W. Uso agrícola da escória de siderurgia no Brasil: estudos na cultura da canade-açúcar. Jaboticabal: Funep, 2001. 67p.

PRADO, R.M.; FERNANDES, F.M.; NATALE, W. Calcário e escória de siderurgia avaliados por análise foliar, acúmulo e exportação de macronutrientes em cana-de-açúcar. Scientia Agricola, Piracicaba, v.59, n.1, p.129-135, 2002.

RAID, R.N.; ANDERSON, D.L.; ULLOA, M.F. Influence of cultivar and amendment of soil with calcium silicate slag on foliar disease development and yield of sugar cane. Crop Protection, Amsterdam, v.11, n.1, p.84-88, 1992.

RAIJ, B. van. Fertilidade do solo e adubação. São Paulo; Piracicaba: Ceres, Potafos, 1991. 343p.

SANTOS, A.R. Diagnose nutricional e respostas do capim braquiária submetido a doses de nitrogênio e enxofre. 1997. 115f. Tese (Doutorado em Solos e Nutrição de Plantas) - Escola Superior de Agricultura "Luiz de Queiroz", Universidade de São Paulo. Piracicaba.

SANTOS, I.P.A. Resposta a fósforo, micorriza e nitrogênio de braquiarão e amendoim forrageiro consorciados. 1999. 158f. Dissertação (Mestrado em Solos e Nutrição de Plantas) Universidade Federal de Lavras, Lavras.

SAS INSTITUTE (Cary, Estados Unidos). Software and services: system for Windows, versão 9.0: software. Cary, 2002.

WALLACE, A. Relacionships among nitrogen, silicon and heavy metal uptake by plants. Soil Sciense, Baltimore, v.147, n.6, p.457-460, 1989.
WERNER, J.C.; PAULINO, V.T.; CANTARELLA, H; ANDRADE, N.O.; QUAGGIO, J.A. Recomendação de adubação e calagem para forrageiras. In: RAIJ, B. van; CANTARELLA, H.; QUAGGIO, J.A.; FURLANI, A.M.C. Recomendação de adubação e calagem para o Estado de São Paulo. 2. ed. rev. Campinas: Instituto Agronômico. 1997. p.261-274. (Boletim técnico, 100) 